\title{
Influence of compaction on the properties of remoulded cemented sands
}

\author{
Aseel R. Al-Sanea and Nabil F. Ismael* \\ Civil Engineering Department, Kuwait University, Kuwait. \\ *Corresponding Author: nabil.ismael@ku.edu.kw
}

Submitted :21/05/2021

Revised :26/08/2021

Accepted :06/09/2021

\begin{abstract}
The properties and behaviour of compacted cemented sands in Kuwait were examined by laboratory and model tests. Upon excavation, the cementation bonds are destroyed, and the material, locally known as gatch, is transformed into clayey sands with fines content $(<0.075 \mathrm{~mm})$ ranging from $20 \%$ to $40 \%$. Testing included basic properties, compaction, permeability, direct shear, and consolidation tests. Model tests were also carried out on a circular plate loaded on compacted soils to failure. The test soil was compacted to a relative compaction of $85 \%, 90 \%, 95 \%$, and $100 \%$. The results indicate a significant decrease in the ultimate bearing capacity and the shear strength parameters $\mathrm{c}, \phi$, and an increase in the compressibility parameters $\mathrm{Cc}, \mathrm{Cs}$, and the permeability as the relative compaction decreases from $100 \%$ to $85 \%$. The rate of variation of the various soil parameters with relative compaction is examined.
\end{abstract}

Keywords: Relative compaction; Remoulded cemented sands; Direct shear tests; Consolidation tests; Permeability; Model tests.

\section{INTRODUCTION}

Major deposits of cemented sands exist in the state of Kuwait either at ground level or below a layers of surface windblown sands (Ismael et al. 1986). The excess of evaporation over rainfall even in the winter season leads to the precipitation of cementing agents, which are deposited at the points of contact between the particles (Krynine and Judd 1957) causing bonding and cementation and the formation of cemented layers. The cementing agents include calcium and magnesium carbonates and calcium sulphates (gypsum). The degree of cementation varies from site to site, and at different depths at the same site. These materials are strongly anisotropic and possibly moisture sensitive (Barton 1993). Recent research dealt only with the laboratory determination of the geotechnical properties of a few cemented sand samples and the role of cementation in increasing the strength parameters c, $\phi$ (Clough et al. 1981, Saxena and Lastrico 1978). In Kuwait city, the depth of these competent deposits varies from 0 to $7 \mathrm{~m}$, and they are usually overlain by surface desert sands. Their properties and behaviour were examined in detail (Ismael 1999, Ismael 1993, Ismael et al. 1986). Upon excavation, the cementation bonds are destroyed, and the material, locally known as gatch, is transferred into silty sands or clayey sands with fine content $(<0.075 \mathrm{~mm})$ ranging from 20 to $50 \%$. It is used as a backfill material for various engineering and earthwork construction projects. All specifications require a 
certain degree of compaction defined by the relative compaction, which is the ratio of the compacted dry density in the field to the maximum laboratory value as determined by the Standard or the Modified Proctor Test. This degree of compaction usually varies between $90 \%$ and $100 \%$. It is of great interest to know the influence of relative compaction on the soil properties and behaviour under the applied loads.

Toward this goal, a comprehensive laboratory soil testing program was carried out on a clayey sand "gatch" soil taken from one site in Kuwait. Testing on the remoulded samples included basic properties, direct shear, and consolidation and permeability tests on samples compacted to a relative compaction of $100 \%, 95 \%, 90 \%$, and $85 \%$. Model tests were also carried out at these relative compaction values on circular steel plate loaded in a sand box to failure. This paper presents the results with emphasis on the influence of relative compaction on the strength parameters, compressibility, and permeability. Also, the effect on the ultimate bearing capacity and settlement under the applied loads is examined from the results of the model tests. The results emphasize the importance of the field compaction for proper and the safe earth work construction.

\section{THE TEST SOIL AND THE TESTING PROGRAM}

The basic properties of the soil employed herein and its compaction characteristics were determined by Sobhy (2021). The bulk samples of the gatch soil were collected from a depth of 1 to $1.5 \mathrm{~m}$ from a site in Al-Ardiya, Kuwait city, Kuwait. This material is cemented; however, upon excavation, the cementation bonds are crushed. The principal component is quartz, which constitutes $65 \%$ of the total composition with carbonates and sulphates occupying most of the remaining composition and decreasing with depth. It was classified as clayey sand or "SC" according to the Unified Soil Classification System. It has fines content $(<0.075 \mathrm{~mm})$ of $21.3 \%$ and no gravel, liquid and plastic limits of $36.3 \%$ and $23.4 \%$, respectively, and a plasticity index of $\mathrm{PI}=12.9 \%$. The following tests were performed on samples prepared at maximum density and optimum moisture content, that is, relative compaction " $\mathrm{RC} "=100 \%$, and on samples compacted to $\mathrm{RC}=95 \%, 90 \%$, and $85 \%$ and optimum moisture content:

1. Direct shear tests on samples $63 \mathrm{~mm}$ diameter and $20 \mathrm{~mm}$ thick. The tests were carried out according to ASTM D3080 standard.

2. Consolidation tests on samples $75 \mathrm{~mm}$ diameter and $20 \mathrm{~mm}$ thick according to ASTM D2435 standard.

3. Falling head permeability tests on samples $100 \mathrm{~mm}$ diameter and $130 \mathrm{~mm}$ height according to ASTM D5084 standard.

4. Model tests on $70 \mathrm{~mm}$ diameter steel plate loaded in a sand box measuring $0.3 \mathrm{~m} * 0.3 \mathrm{~m} * 0.28 \mathrm{~m}$ deep. The load was applied at constant rate of strain of $1.4 \mathrm{~mm} / \mathrm{min}$ with readings taken at each $1 \mathrm{~mm}$ penetration intervals until the ultimate bearing capacity failure was reached. The ultimate load was defined by continuous penetration at constant pressure.

\section{SAMPLE PREPARATION}

For the direct shear, consolidation, and permeability tests, the samples were placed in four layers and tamped to reach the required density. As for the model tests, the soil was placed so that it will reach $50 \mathrm{~mm}$ thick layers after compaction by tamping to the required relative compaction. In all tests, the soil had a moisture content equal to the optimum value. 


\section{TEST RESULTS}

The Modified Proctor Compaction Test results are shown in Figure 1. The maximum dry density and the optimum moisture content are $1895 \mathrm{~kg} / \mathrm{m}^{3}$ and 12.8\%, respectively. Figures 2 and 3 show the variation of the shear strength parameters $\phi, c$, respectively, with relative compaction as determined from the direct shear tests. The friction angle $\phi$ increased significantly from $30^{\circ}$ to $37.5^{\circ}$ as the relative compaction increased from $85 \%$ to $90 \%$. Then, it increased by $2^{\circ}$ corresponding to RC increase from $90 \%$ to $95 \%$, and by $2^{\circ}$ when RC increased from $95 \%$ to $100 \%$. The increase in cohesion c with RC was modest with a $15 \mathrm{kPa}$ increase when RC increased from $90 \%$ to $100 \%$. Figure 4 shows a comparison of the shear stress vs. relative lateral displacement for samples compacted to $\mathrm{RC}=$ $100 \%$ and $90 \%$. The relative lateral displacement is the ratio of the shear displacement to the maximum value of 5 $\mathrm{mm}$, which can be recorded by the direct shear apparatus. As shown, softer response is obtained when $\mathrm{RC}=90 \%$ with lower modulus and no clear peak stress as compared to the results for samples having $\mathrm{RC}=100 \%$. A summary of all test results is given in Table 1.

The consolidation test results are plotted in Figure 5 in the form of e-logo plots. The variation of the compressibility parameters $\mathrm{C}_{\mathrm{c}}, \mathrm{C}_{\mathrm{s}}$ with relative compaction is shown in Table 1 . The values of these parameters and the coefficient of consolidation $\mathrm{C}_{\mathrm{v}}$, free swell, and the zero swell pressure are given in Table 1. The free swell and the zero swell pressures were determined from the conventional consolidation test (Das 2016). The specimen is placed in an oedometer under a small surcharge of $6.9 \mathrm{kN} / \mathrm{m}^{2}$, and water is added to the specimen allowing it to swell and reach an equilibrium position after some time. The ratio of the measured deformation to the original height is the free swell. Load is then applied in steps, and the specimen is consolidated. From the plot of the deformation vs. $\log \sigma$ ' , when $\sigma^{\prime}$ is the effective stress, the pressure corresponding to the initial condition or zero deformation is the zero swell pressure, $\sigma^{\prime}$ sw. With increasing relative compaction, the compressibility decreased. The compression index decreased significantly as RC increased from $85 \%$ to $90 \%$ and then decreased from 0.0356 to 0.0242 , a $32 \%$ decrease as RC increased from $90 \%$ to $100 \%$. No change in the swell index was observed between RC $=85 \%$ and $90 \%$, and a small reduction between $\mathrm{RC}=90 \%$ and $100 \%$ was observed. Although the values of $\mathrm{C}_{\mathrm{c}}$ and $\mathrm{C}_{\mathrm{s}}$ are all small, they show clearly a significant reduction of compressibility as the relative compaction increased.

Table 1 shows the variation of the free swell and the zero swell pressure with relative compaction as obtained from the consolidation test results. All samples were compacted at the optimum moisture content. As expected, the free swell and the zero swell pressure increased with relative compaction. The free swell increased from $0.75 \%$ to $1.021 \%$, and the zero swell pressure increased from $39.45 \mathrm{kPa}$ to $62.3 \mathrm{kPa}$ as the relative compaction increased from $90 \%$ to $100 \%$. This amounts to $36 \%$ and $58 \%$ increase in the free swell and the zero swell pressure, respectively. As expected, larger free swell and zero swell pressure occurred with soil with larger density. It is noted, however, that the maximum free swell for this soil at $\mathrm{RC}=100 \%$ is limited to about $1 \%$ indicating a non-swelling soil. The average values of the coefficient of consolidation $\mathrm{C}_{\mathrm{v}}$ for all $\mathrm{RC}$ values are given in Table 1 . It is noted that all values at different relative compaction are nearly the same except at $\mathrm{RC}=90 \%$, where a lower value was recorded. The difference, however, is not significant noting that all values are small. 


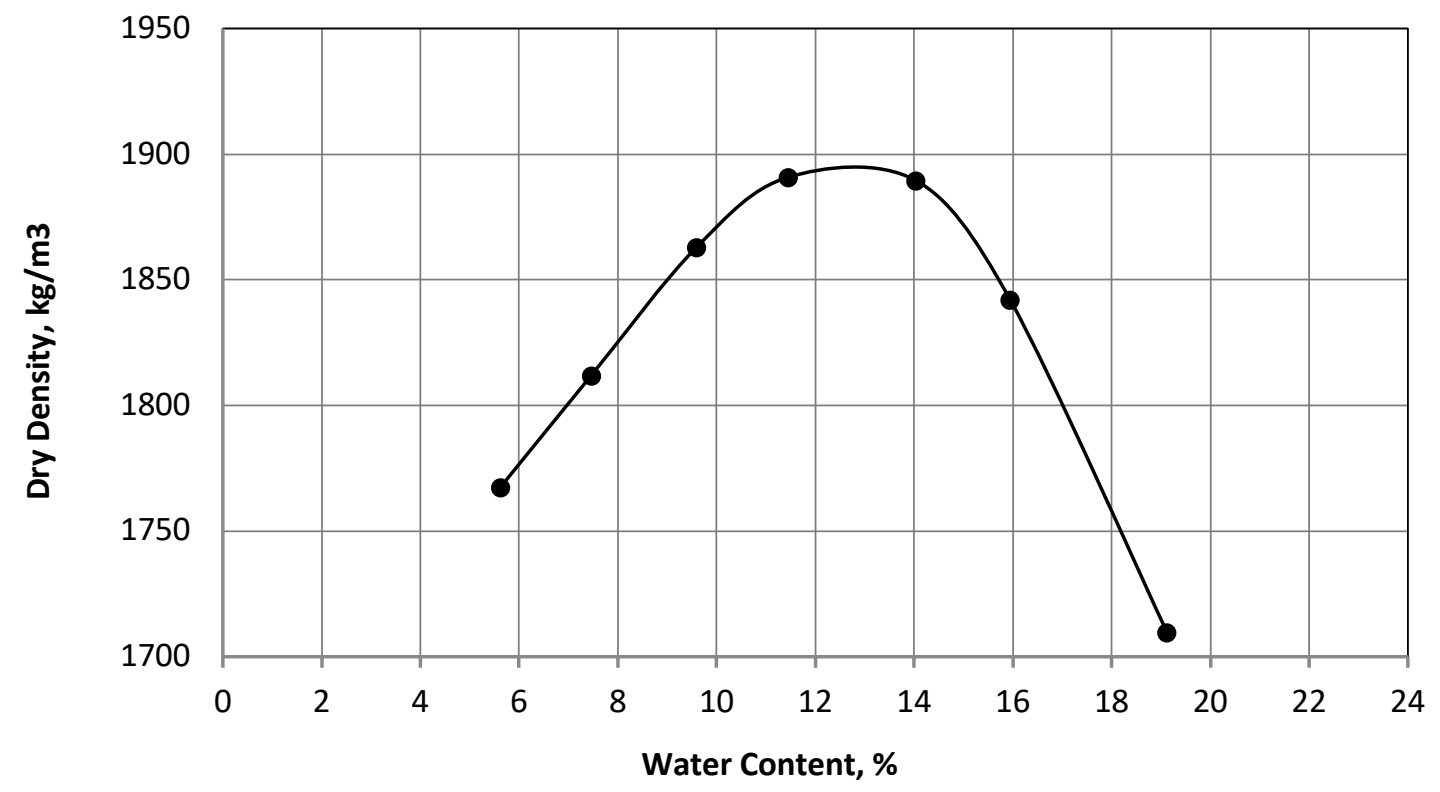

Figure 1. Compaction test results (after Sobhy 2021).

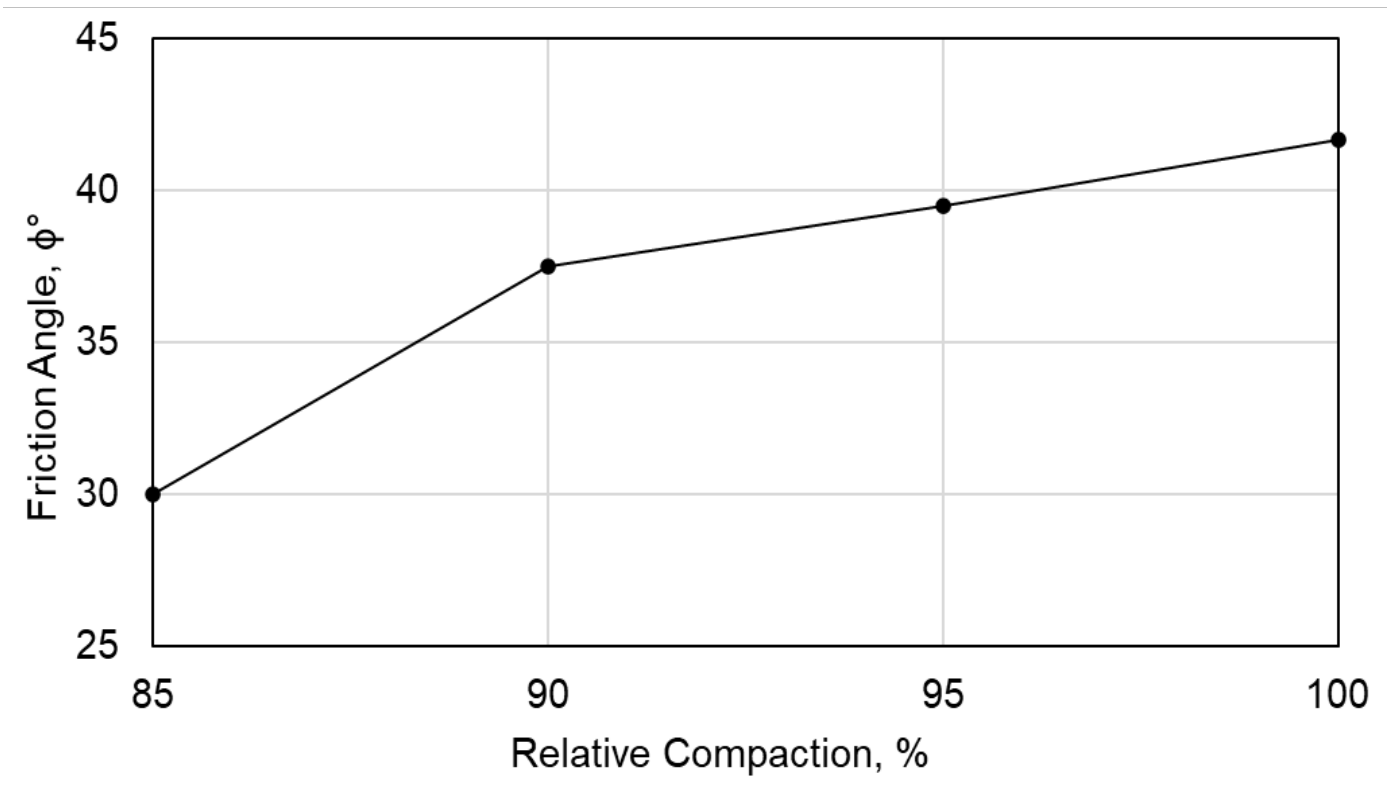

Figure 2. Variation of the friction angle $\phi$ with relative compaction. 


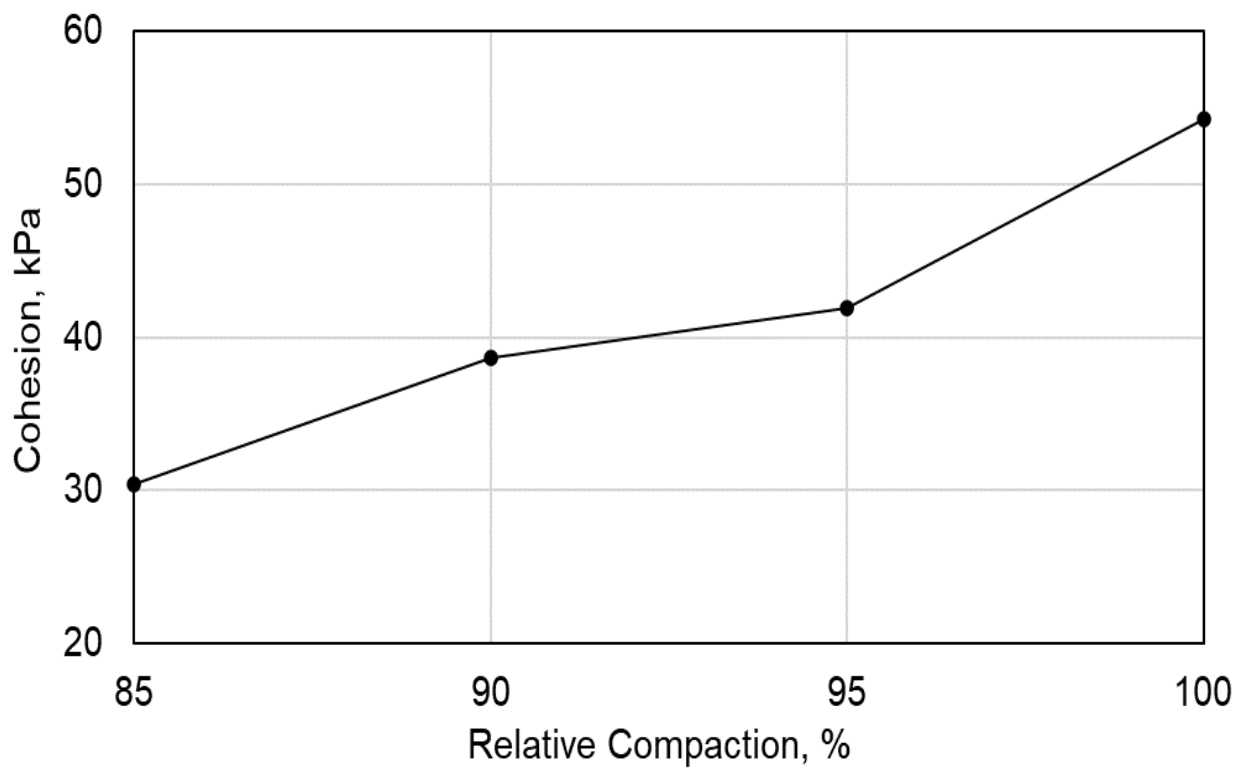

Figure 3. Variation of the cohesion with relative compaction

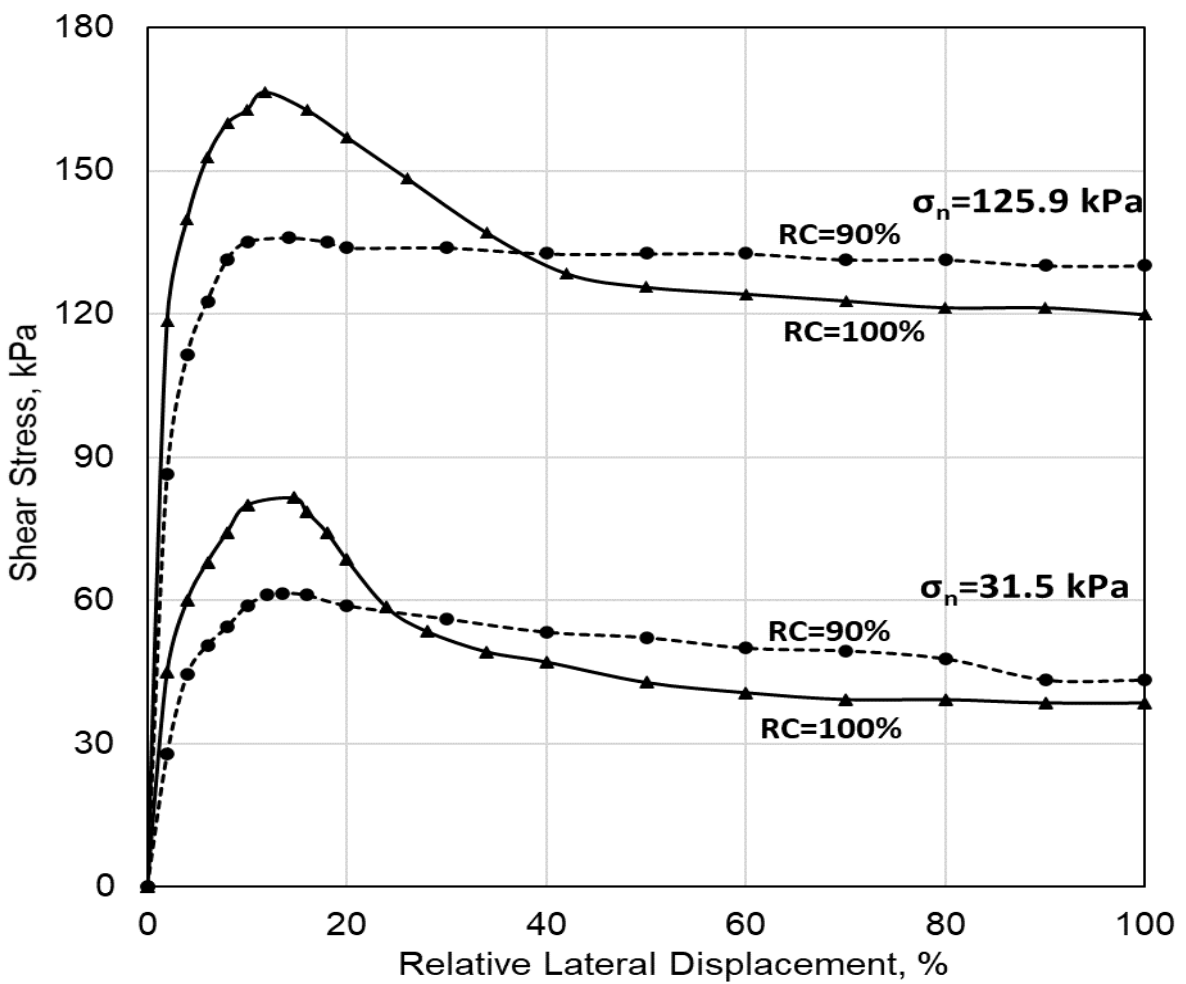

Figure 4. Shear stress vs. relative lateral displacement for samples compacted to relative compaction of $100 \%$ and $90 \%$. 
Table 1. Summary of Test Results.

\begin{tabular}{|c|c|c|c|c|}
\hline \multirow{2}{*}{ Parameters } & \multicolumn{4}{|c|}{ Relative Compaction ( \% ) } \\
\cline { 2 - 5 } & 100 & 95 & 90 & 85 \\
\hline$\rho_{\mathrm{d}}\left(\mathrm{kg} / \mathrm{m}^{3}\right)$ & 1895 & 1800.25 & 1705.5 & 1610.75 \\
\hline $\mathrm{w}(\%)$ & 12.8 & 12.8 & 12.8 & 12.8 \\
\hline$\phi^{\circ}$ & 41.7 & 39.5 & 37.5 & 30 \\
\hline $\mathrm{C}(\mathrm{kPa})$ & 54.3 & 41.9 & 38.7 & 30.4 \\
\hline $\mathrm{C}_{\mathrm{c}}$ & 0.0242 & 0.0289 & 0.0356 & 0.136 \\
\hline $\mathrm{C}_{\mathrm{s}}$ & 0.0099 & 0.012 & 0.013 & 0.013 \\
\hline Avg. $\mathrm{C}_{\mathrm{v}}\left(\mathrm{mm}{ }^{2} / \mathrm{min}\right)$ & 649 & 648 & 542.7 & 626 \\
\hline Free Swell $(\%)$ & 1.021 & 0.884 & 0.75 & 0.63 \\
\hline Swell Pressure $(\mathrm{kPa})$ & 62.3 & 49.84 & 39.45 & 32.2 \\
\hline $\mathrm{k}(\mathrm{cm} / \mathrm{sec})$ & $0.83 * 10^{-8}$ & $5.7 * 10^{-8}$ & $11.5^{*} 10^{-8}$ & $51.8^{*} 10^{-8}$ \\
\hline Ultimate Bearing Capacity $(\mathrm{kPa})$ & 7491.5 & 4513.9 & 2766.4 & 1388.5 \\
\hline
\end{tabular}

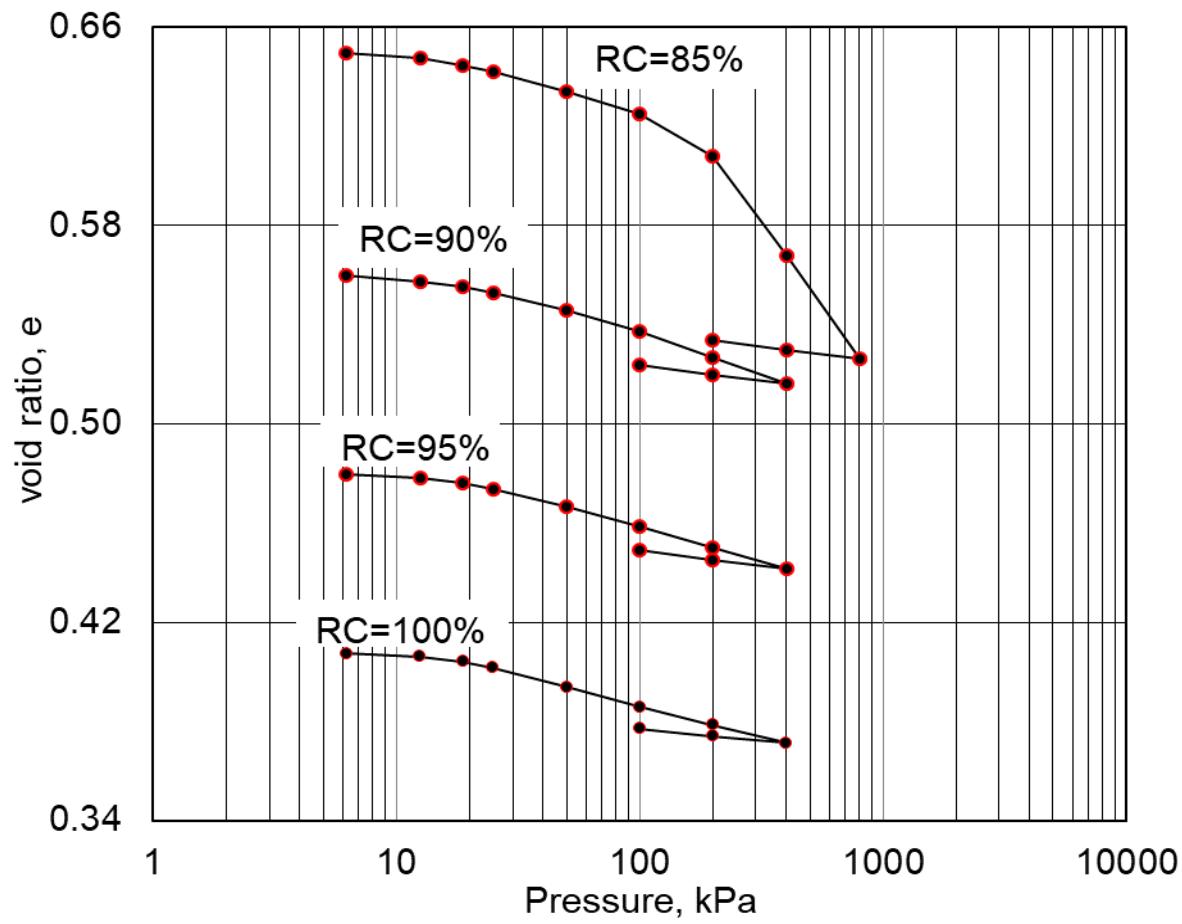

Figure 5. e- $\log \sigma$ plots from consolidation tests. 
Table 1 shows the variation of the coefficient of permeability $\mathrm{k}$ with relative compaction. As shown, the values of $\mathrm{k}$ decreased significantly with increasing relative compaction particularly when it increased from $85 \%$ to $90 \%$. As $\mathrm{RC}$ increased from $90 \%$ to $95 \%$, the values of $\mathrm{k}$ decreased from $11.5^{*} 10^{-8} \mathrm{~cm} / \mathrm{sec}$ to $5.7 * 10^{-8} \mathrm{~cm} / \mathrm{sec}$. which correspond to a $50 \%$ decrease in the coefficient of permeability. For the range of relative compaction between $95 \%$ and $100 \%, \mathrm{~K}$ decreased from $5.7 * 10^{-8} \mathrm{~cm} / \mathrm{sec}$ to $0.83 * 10^{-8} \mathrm{~cm} / \mathrm{sec}$, or an $85 \%$ decrease in the coefficient of permeability. These measurements indicate the importance of proper compaction of soils around foundations and earth structures to reach low permeability and prevent large flow of water and deterioration of concrete structures.

\section{COMPARISON BETWEEN NATURAL AND REMOLDED SAMPLES}

All tests in the present research were conducted on remoulded samples. To examine the effect of soil disturbance and the crushing of the cementation bonds on the strength of cemented sands, several studies were carried out (Ismael 1999, Abdelsalam and Ismael 2018). Consolidated undrained triaxial tests with pore pressure measurement on natural cemented samples and on remoulded samples to the same unit weight revealed that remoulding resulted in the loss of the cohesion component of the strength $\mathrm{c}$ and a slight decrease of 1 degree in the angle of friction $\phi$. The stiffness also decreased due to remoulding as the initial or secant modulus values were lower for remoulded specimens compared to natural undisturbed specimens sheared at the same confining pressure.

Based on the above, it is always recommended to place the foundations on the natural undisturbed gatch soil to benefit from the higher strength and lower compressibility as compared to the disturbed compacted ground.

\section{MODEL TESTS}

Model tests were performed to determine the effect of relative compaction on the ultimate bearing capacity and settlement of shallow foundations. A sand box measuring $0.3 \mathrm{~m} * 0.3 \mathrm{~m} * 0.28 \mathrm{~m}$ deep was employed, and a $70 \mathrm{~mm}$ diameter steel plate was placed on the surface at the centre, and loaded until failure occurred. The soil was placed in layers compacted to reach the required relative compaction and optimum moisture content. Loading was applied at a constant rate of strain with readings taken at each $1 \mathrm{~mm}$ of vertical deformation. Figure 6a shows the load test set up. Punching shear failure occurred in all tests with radial cracks extending in all directions and no heave of the soil surface around the plate. This is shown in Figure 6b. The pressure vs. settlement curves for all tests are plotted in Figure 7. The ultimate bearing capacity values are summarized in Table 1, and their variation with relative compaction is plotted in Figure 8. The ultimate pressure was taken at the point at which continuous deformation was occurring at no change in the load.

Although the failure mode is the same for all tests, the above results indicate a major increase in the ultimate bearing capacity with increase in relative compaction. The ultimate bearing capacity increased from $2766.4 \mathrm{kPa}$ to $4513.9 \mathrm{kPa}$ as RC increased from $90 \%$ to $95 \%$, respectively, thus increasing by $63 \%$. Similarly, for RC $=100 \%$, the measured ultimate bearing capacity was $7491.5 \mathrm{kPa}$, which represents an increase of $66 \%$ over the corresponding value at $\mathrm{RC}=95 \%$ and 2.71 times increase over the value at $\mathrm{RC}=90 \%$. With regard to deformation under the applied loads, it is observed that the pressure vs. settlement curves remained linear and elastic up to a pressure of $1500 \mathrm{kPa}$ for tests on soils compacted to $100 \%$ and $95 \%$ relative compaction as shown in Figure 7 . At this pressure, the soil with $\mathrm{RC}=90 \%$ had $14 \mathrm{~mm}$ of settlement surpassing the elastic range, while tests on soil compacted to $\mathrm{RC}=85 \%$ failed before this pressure was reached. 


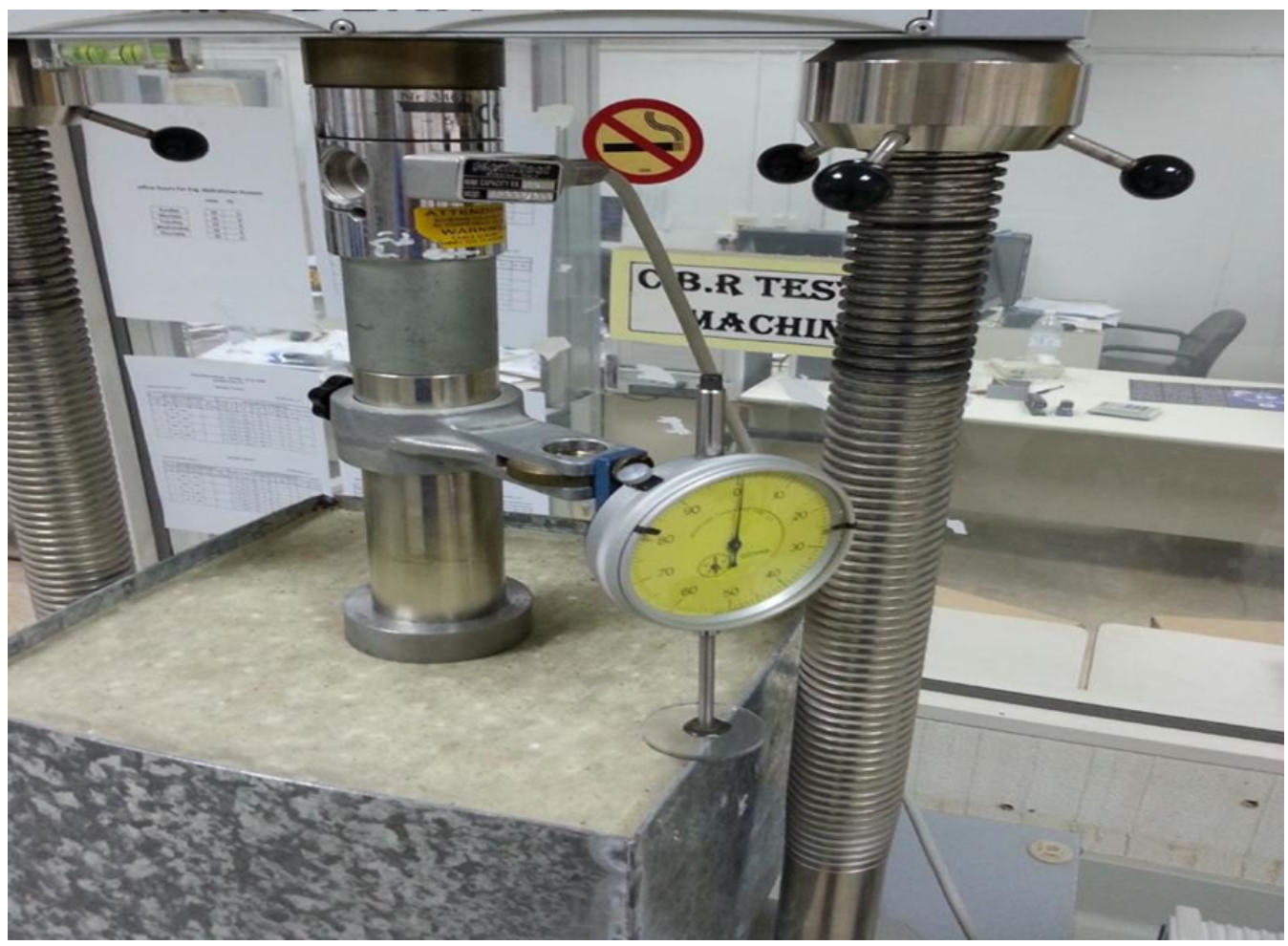

Figure 6a. Load test set up on clayey sand (gatch) soil.

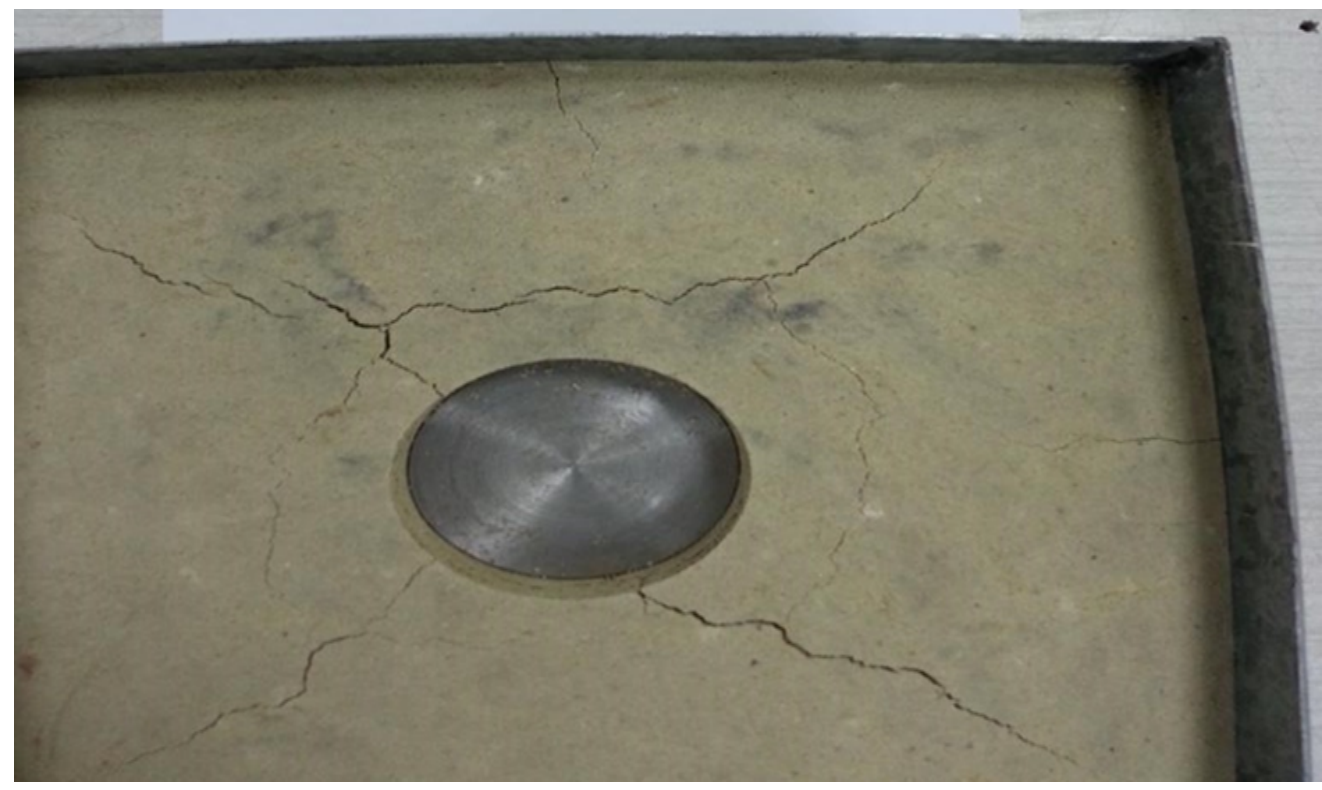

Figure 6b. After failure view showing punching failure and radial cracks $(\mathrm{RC}=90 \%)$. 


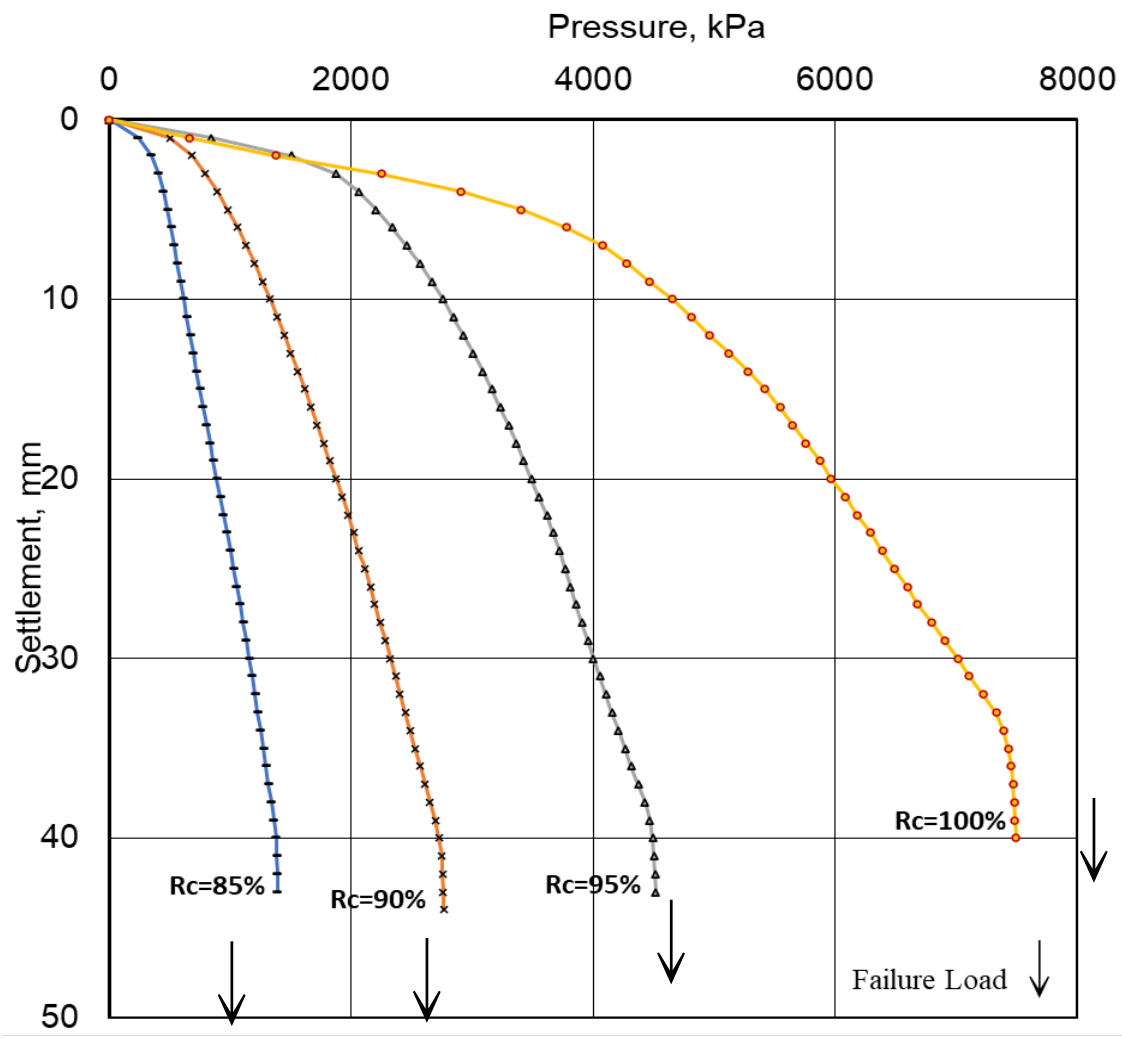

Figure 7. Pressure vs. settlement at relative compaction of $85 \%, 90 \%, 95 \%, 100 \%$.

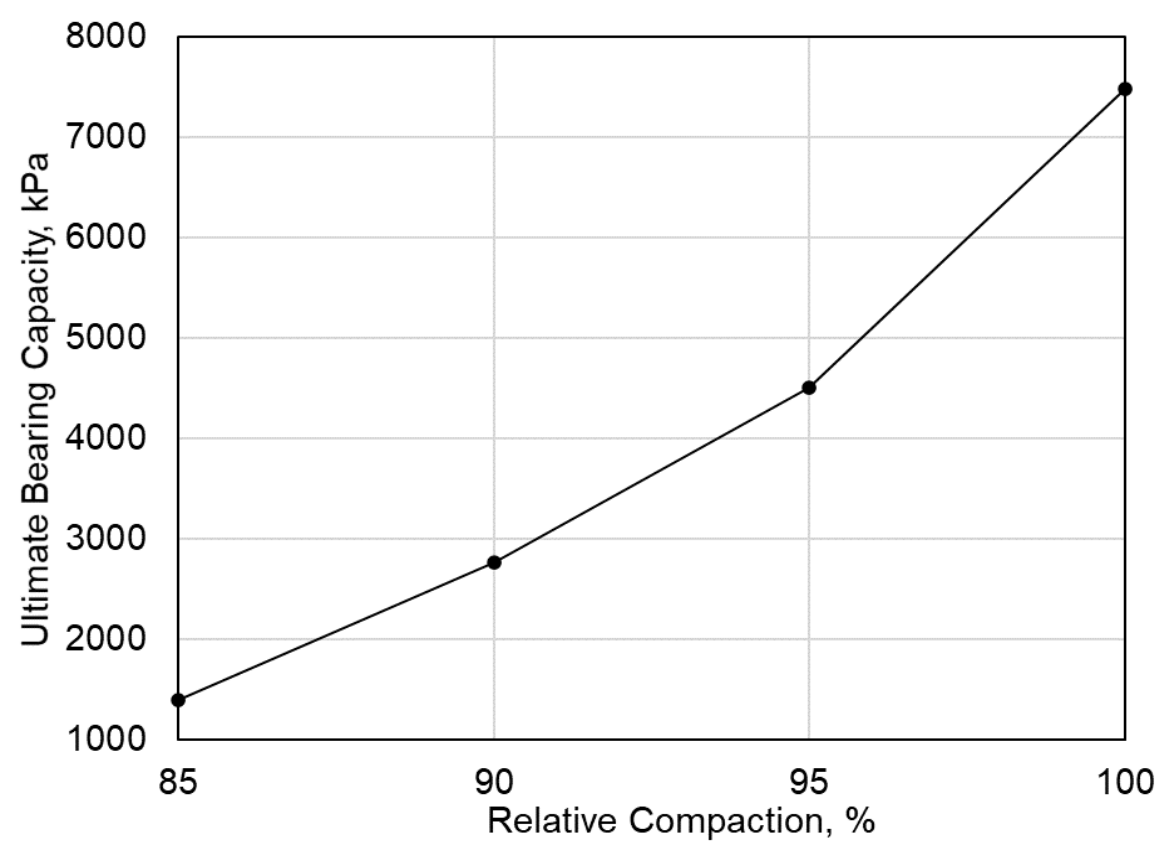

Figure 8. Ultimate Bearing capacity vs. relative compaction from model tests. 


\section{DISCUSSION AND PRACTICAL APPLICATIONS}

For the clayey sand (gatch) of the present research, the laboratory tests indicate the influence of relative compaction on the soil behaviour and parameters. When RC increased from $90 \%$ to $95 \%$ and from $95 \%$ to $100 \%$, the angle of internal friction $\phi$ increased by $2^{\circ}$, and the ultimate bearing capacity increased by $63 \%$ and $66 \%$, respectively. All values are given in Table 1. Along with the increase in strength and stiffness, the compressibility decreased as the relative compaction increased. The increase in the free swell from $0.75 \%$ to $1.021 \%$ for $\mathrm{RC}=90 \%$ to $100 \%$, respectively, is considered modest indicating a nonswelling soil. The corresponding zero swell pressure was 39.45 $\mathrm{kPa}$ and $62.3 \mathrm{kPa}$, respectively. It should be emphasized that all samples were prepared at the optimum moisture content. Table 1 shows a significant reduction in the coefficient of permeability with increasing RC. The value at $\mathrm{RC}=90 \%$ was $11.5^{*} 10^{-8} \mathrm{~cm} / \mathrm{sec}$ compared to $0.83 * 10^{-8} \mathrm{~cm} / \mathrm{sec}$ at $\mathrm{RC}=100 \%$, which indicate a $92.8 \%$ reduction in magnitude.

The above results indicate the importance of increasing the compaction effort and the relative compaction in the field. The corresponding increase in strength and bearing capacity and the decrease in compressibility and permeability are significant and require attention and proper supervision and monitoring in the field.

\section{CONCLUSIONS}

The influence of relative compaction on the soil parameters and bearing capacity of a remoulded clayey sand in Kuwait was examined by laboratory soil tests and by model tests. Based on the test results, the following conclusions were reached:

1. With increasing relative compaction, the strength parameters $\mathrm{c}, \phi$ increased. The angle of friction $\phi$ increased by two degrees as the relative compaction RC increased from $90 \%$ to $95 \%$ and by two degrees as RC increased from $95 \%$ to $100 \%$. A small increase of the cohesion c is also noted.

2. The compressibility decreased with increasing relative compaction. The compression index $\mathrm{C}_{\mathrm{c}}$ decreased from 0.0356 for $\mathrm{RC}=90 \%$ to 0.0289 for $\mathrm{RC}=95 \%$ and to 0.0242 for $\mathrm{RC}=100 \%$. However, all values are small in magnitude.

3. The free swell and the swell pressure increased when the relative compaction increased.

4. The coefficient of permeability $\mathrm{k}$ decreased significantly with relative compaction. It decreased from $11.5^{*} 10^{-8}$ $\mathrm{cm} / \mathrm{sec}$ to $5.7^{*} 10^{-8} \mathrm{~cm} / \mathrm{sec}$, and $0.83 * 10^{-8} \mathrm{~cm} / \mathrm{sec}$ as RC increased from $90 \%$ to $95 \%$ and $100 \%$, respectively.

5. The model tests indicated that the ultimate bearing capacity of a circular plate increased from $2766.4 \mathrm{kPa}$ to $4513.9 \mathrm{kPa}$ and $7491.5 \mathrm{kPa}$ as the relative compaction increased from $90 \%$ to $95 \%$ and $100 \%$, respectively. This corresponds to successive increases of $63 \%$ and $66 \%$ in the ultimate bearing capacity.

6. The importance of high relative compaction values " $\mathrm{RC}$ " is confirmed by the test results. A significant increase in the strength parameters and ultimate bearing capacity is achieved with increasing relative compaction, in addition to reduced compressibility and permeability. This is highly desirable for proper foundation design and construction. 


\section{REFERENCES}

Abdelsalam, Z.,and Ismael, N. 2018. Effect of ground disruption on the strength of Gatch soil in Kuwait, Geotechnical Engineering Journal of the SEAGS \& AGSSEA, Vol. 49 No. 3, pp. 23-26.

Barton, M.E. 1993. Cohesive sands: the natural transition from sands to sandstones. Proc. of an Int. Symp. Geotechnical Engineering of Hard Soils - Soft Rocks, Athens, Greece, 20-23 Sept., A.A. Balkema Publishers, pp. 367-374.

Clough, G.W., Sitar, N., Bachus, R.C., and Rad, N.S. 1981. Cemented sands under static loading, J. Geotech. Engrg., ASCE, Vol. 107, No. 5, pp. 799-817.

Das, B.M. 2016. Principles of Foundation Engineering, 8th edition SI, Cengage Learning, Boston, U.S.A., p. 572.

Ismael, N.F. 1999. Properties and behavior of cemented sand deposits in Kuwait. Soils and Foundations, Japanese Geotechnical Society, Japan, No. 4, Vol. 39, pp. 47-57.

Ismael, N.F. 1993. Influence of cementation on the properties and bearing capacity of arid climate soils. Proc. of an Int. Symp. Geotech. Engrg. of Hard Soils - Soft Rocks, Athens, Greece, 20-23 Sept., A.A. Balkema, pp. $953-$ 959.

Ismael, N.F., Mollah, M.A., and Al-Khalidi, O. 1986. Geotechnical properties of cemented soils in Kuwait. Australian Road Research Journal, Vol.16, No.2, pp.94-104.

Krynine, D.P. and Judd, W.R. 1957. Principles of Engineering Geology and Geotechnics, McGraw-Hill, New York, N.Y.

Saxena, S.K., and Lastrico, R.M. 1978. Static properties of lightly cemented sand, J. Geotech. Engrg., ASCE, Vol. 104, No. 12, pp. 1449-1464.

Sobhy, N. 2021. Effect of ground tire rubber additive on the behavior of remolded gatch soil in Kuwait. M.Sc. thesis. 